\title{
Sistem Pendukung Keputusan Pembagian Kelas Unggulan Siswa Baru Menggunakan Metode Promethee Pada STM Raksana Medan
}

\author{
Junaidi \\ STMIK Budi Darma Medan, Jl. Sisimangaraja No.338 Simpang Limun, Medan, Indonesia \\ nurasyiah1211@gmail.com
}

\begin{abstract}
Abstrak. Pendidikan mempunyai peranan yang amat menentukan, tidak hanya bagi perkembangan dan perwujudan diri individu tetapi juga bagi pembangunan suatu bangsa dan negara. Kemajuan suatu kebudayaan tergantung dari bagaimana kebudayaan tersebut mengenali, menghargai, dan memanfaatkan sumber daya manusianya. Hal tersebut berkaitan erat dengan kualitas pendidikan yang diberikan kepada anggota-angota masyarakatnya.Kata keputusan berarti pilihan, yaitu pilihan dari dua atau lebih kemungkinan. Pengambilan keputusan hampir tidak merupakan pilihan antara yang benar dan yang salah tetapi justru yang sering terjadi adalah pilihan antara yang "hampir benar" dan yang "mungkin salah". Pengambilan keputusan di dalam suatu organisasi merupakan hasil proses komunikasi dan partisipasi yang terus menerus dari keseluruhan organisasi. Hasil keputusan tersebut dapat merupakan pernyataan yang disetujui antaralternative atau antarprosedur untuk mencapai tujuan tertentu. Namun untuk dapat menentukan keputusan yang terbaik ada beberapa metode yang dapat digunakan untuk membangun sebuah sistem pendukung keputusan salah satunya adalah Promethee. Metode promethee termasuk kedalam kelompok pemecahan Multi Criteria Decision Making (MCDM) atau pengambilan keputusan kriteria majemuk yang merupakan disiplin ilmu yang sangat penting dalam pengambilan keputusan atas suatu masalah yang memiliki lebih dari satu kriteria (multikriteria).
\end{abstract}

Kata Kunci : Pendidikan, keputusan, organisasi, MCDM, Promethee.

Abstract. Education has a very decisive role, not only for the development and manifestation of individuals but also for the development of a nation and a state. The progress of a culture depends on how that culture recognizes, appreciates, and uses its human resources. This is closely related to the quality of education provided to members of the community. The word decision means choice, namely the choice of two or more possibilities. Decision making is hardly a choice between right and wrong but what often happens is a choice between "almost right" and "maybe wrong". Decision making in an organization is the result of a continuous process of communication and participation from the entire organization. The results of these decisions can be statements that are agreed between alternatives or between procedures to achieve certain goals. However, to be able to determine the best decision, there are several methods that can be used to build a decision support system, one of which is Promethee. The promethee method is included in the Multi Criteria Decision Making (MCDM) group solving or multiple criteria decision making which is a discipline that is very important in making decisions on a problem that has more than one criterion (multicriteria).

Keyword : Education, decisions, organizations, MCDM, Promethee

\section{PENDAHULUAN}

Pendidikan mempunyai peranan yang amat menentukan, tidak hanya bagi perkembangan dan perwujudan diri individu tetapi juga bagi pembangunan suatu bangsa dan negara. Kemajuan suatu kebudayaan tergantung dari bagaimana kebudayaan tersebut mengenali, menghargai, dan memanfaatkan sumber daya manusianya. Hal tersebut berkaitan erat dengan kualitas pendidikan yang diberikan kepada anggota-angota masyarakatnya. Dengan asas pemerataan kesempatan belajar merupakan penerapan dari asas demokrasi dan bertitik tolak pada kesempatan pendidikan yang sama dan harus diberikan kepada warga negara Indonesia, baik secara normal maupun berlainan. Memberikan kesempatan pendidikan yang sama pada hakikatnya berarti mengusahakan suatu lingkungan dimana semua anak mendapat kesempatan yang sama untuk mewujudkan potensi secara optimal[1], [2]. 
Namun dalam kenyataannya pendidikan saat ini masih biasa-biasa saja, yakni masih banyaknya sekolah dengan kelas reguler, atau pembagian kelas siswa berdasarkan nomor urut pendaftaran. Hal tersebut tentunya akan berpengaruh terhadap proses belajar-mengajar seperti dalam penyampaian materi dan metode belajar yang digunakan[3].

Proses pembagian kelas setiap tahun ajaran baru biasanya masih dilakukan secara konvensional, yakni dengan metode acak maupun metode pengurutan dan belum melibatkan kemajuan dibidang teknologi informasi, khususnya melibatkan tekhnologi sistem cerdas. Keterlibatan tekhnologi informasi hanya digunakan untuk mengurutkan jumlah nilai siswa. Dengan menggunakan spreadsheet, pembuatan daftar calon dengan urutan prestasi dari yang paling pandai sampai yang paling lemah dapat dilakukan dengan mudah[4], [5].

Untuk menyeleksi calon siswa yang diterima cukup dengan mengambil sejumlah calon siswa yang terdapat pada ranking paling atas sesuai dengan kapasitas. Calon siswa yang berada pada urutan diluar kapasitas, dinyatakan tidak diterima. Proses pembagian kelas dengan menggunakan metode konvensional, baik metode acak maupun metode pengurutan, mengakibatkan terjadinya berbagai masalah dalam pengajaran yang diakibatkan karena berkumpulnya calon siswa atau siswa dengan kecerdasan berbeda dalam satu kelas. Adanya kelas yang dibentuk dari siswa dengan kecerdasan yang berbeda akan menyulitkan pengajar untuk memfokuskan penyampaian lebih banyak materi kepada semua siswa, untuk itu perlu adanya keputusan agar dapat menempatkan siswa dengan kecerdasan yang sama pada satu kelas[6].

Kata keputusan berarti pilihan, yaitu pilihan dari dua atau lebih kemungkinan. Pengambilan keputusan hampir tidak merupakan pilihan antara yang benar dan yang salah tetapi justru yang sering terjadi adalah pilihan antara yang "hampir benar" dan yang "mungkin salah". Pengambilan keputusan di dalam suatu organisasi merupakan hasil proses komunikasi dan partisipasi yang terus menerus dari keseluruhan organisasi. Hasil keputusan tersebut dapat merupakan pernyataan yang disetujui antaralternative atau antarprosedur untuk mencapai tujuan tertentu[7].

Persoalan pengambilan keputusan pada dasarnya adalah bentuk pemilihan dari berbagai alternatif tindakan yang mungkin dipilih yang prosesnya melalui mekanisme tertentu dengan harapan akan menghasilkan keputusan terbaik. Keputusan yang diambil biasanya dilakukan berdasarkan pertimbangan situasional, bahwa keputusan tersebut adalah keputusan terbaik.

Namun untuk dapat menentukan keputusan yang terbaik ada beberapa metode yang dapat digunakan untuk membangun sebuah sistem pendukung keputusan salah satunya adalah Promethee. Metode promethee termasuk kedalam kelompok pemecahan Multi Criteria Decision Making (MCDM) atau pengambilan keputusan kriteria majemuk yang merupakan disiplin ilmu yang sangat penting dalam pengambilan keputusan atas suatu masalah yang memiliki lebih dari satu kriteria (multikriteria)[8].

Menurut Brans dan Mareschal (1999), Promethee yang merupakan singkatan dari Preference Ranking Organization Methods for Enrichment Evaluations adalah metode outranking yang menawarkan cara yang fleksibel dan sederhana kepada user (pembuat keputusan) untuk menganalisis masalah-masalah multikriteria. Promethee adalah salah satu metode penentuan urutan atau prioritas dalam MCDM ( Multi Criterion Decision Making). Penggunaan promethee adalah menentukan dan menghasilkan keputusan dari beberapa alternatif. Promethee berfungsi untuk mengolah data, baik data kuantitatif dan kualitatif sekaligus. Dimana semua data digabung menjadi suatu dengan bobot penilaian yang telah diperoleh melalui penilaian atau survei[9], [10].

\section{METODE PENELITIAN}

Metode penelitian yang dilakukan dalam pengerjaan penelitian ini yaitu[11]:

1. Studi Literatur

Penulisan ini dimulai dengan studi kepustakaan yaitu proses pengumpulan bahan-bahan referensi baik dari buku, artikel, paper, jurnal, makalah,maupun situs internet mengenai Sistem Pendukung 
Keputusan, metode Promethee serta beberapa referensi lainnya untuk menunjang pencapaian tujuan penelitian.

2. Analisis Data dengan penelitian ke Lapangan (Field Research)

Pada tahap ini dilakukan penelitian yang bertujuan untuk memperoleh data secara langsung dari perusahaan khususnya sekolah melalui riset lapangan

a. Pengumupulan sampel dokumentasi yang berhubungan dengan masalah Pembagian Kelas Unggulan pada Sekolah

b. Mewawancarai pihak yang berkompeten dalam masalah Pembagian Kelas Unggulan pada sekolah.

3. Merancang Desain Sistem

Desain yang dirancang adalah desain user interface dan struktur program Sistem Pendukung Keputusan Pembagian Kelas Unggulan.

4. Implementasi Sistem

Sistem diimplementasikan dalam bentuk perangkat lunak mnggunakan bahasa pemrograman Visual Basic.Net.

5. Pengujian dan Analisis Sistem

Pada tahap ini akan dilakukan pengujian sistem, untuk mencari kesalahan-kesalahan sehinggap dapat diperbaiki. Kemudian akan dilakukan analisis terhadap fokus permasalahan penelitian, apakah sudah sesuai seperti yang diinginkan.

\subsection{Sistem Pendukung Keputusan}

Menurut Scott Morton DSS (Decision Support Systems) didefinisikan sebagai sistem berbasis komputer interaktif, yang membantu para pengambil keputusan untuk menggunakan data dan bebagai model untuk memecahkan masalah-masalah semiterstruktur dan tidak terstruktur. Definisi klasik lainnya untuk Decision Support Systems, diajukan oleh Keen dan Scott Morton (1971), yaitu sistem pendukung keputusan memadukan sumber daya intelektual dari individu dan kapabilitas dari komputer untuk meningkatkan kualitass keputusan. Decision Support Systems adalah sistem berbasis komputer bagi para pengambil keputusan manajemen yang menangani masalah-masalah tidak terstruktur. Menurut Moore dan Chang (1980), Decision Support Systems didefinisikan sebagai sistem yang dapat diperluas agar mampu mendukung analisis data ad hoc dan pemodelan keputusan, berorientasi terhadap perencanaan masa depan, dan digunakan pada interval yang tidak regular dan tidak terencana[8], [12].

\subsection{Metode Preference Ranking Organization Method for Enrichment Evaluation (Promethee)}

Preference ranking organization method for enrichment evaluation (Promethee) adalah suatu metode penentuan urutan (prioritas) dalam analisis multikriteria. Masalah pokoknya adalah kesederhanaan, kejelasan, kestabilan. Dugaan dan dominasi kriteria yang digunakan dalam Promethee adalah penggunaan nilai hubungan outranking[13], [14]. Promethee Methods.http://info.wlu.ca/ wwwmath/courses/graduatecourses/ma536/Promethe.pdf). Prinsip yang digunakan adalah penetapan prioritas alternatif yang telah ditetapkan berdasarkan pertimbangan ( $\forall \mathrm{i}$ | fi $(.) \rightarrow \Re[$ Real $])$, dengan kaidah dasar:

$\operatorname{MaX}\{\mathrm{fl}(\mathrm{X}), \mathrm{f} 2(\mathrm{X}), \mathrm{f} 3(\mathrm{X}), \ldots \mathrm{fk}(\mathrm{X}) \mid \mathrm{X} \in \mathfrak{R}\}$,

dimana $\mathrm{K}$ adalah sejumlah kumpulan alternatif, dan fi $(\mathrm{i}=1,2,3, \ldots, \mathrm{K})$ merupakan nilai atau ukuran relaltif kriteria untuk masing-masing alternatif. Dalam aplikasinya sejumlah kriteria telah ditetapkan untuk menjelaskan K yang merupakan penilaian dari $\mathfrak{R}$ (Real). Promethee termasuk dalam keluarga metode outranking yang dikembangkan oleh B. Roy dan meliputi dua fase:

a. Membangun hubungan outranking dari K.

b. Eksploitasi dari hubungan ini memberikan jawaban optimasi kriteria dalam paradigma permasalahan multikriteria. 
Dalam fase pertama, nilai hubungan outranking berdasarkan pertimbangan dominasi masingmasing kriteria indeks preferensi ditentukan dan nilai outranking secara grafis disajikan berdasarkan preferensi dari pembuat keputusan. Data dasar untuk evaluasi dengan metode Promethee disajikan sebagai berikut[15]:

Tabel 1. Data Dasar Analisis Promethee

\begin{tabular}{|c|c|c|c|c|c|c|}
\hline \multirow{2}{*}{ Alternatif } & \multicolumn{6}{|c|}{ Kriteria } \\
\cline { 2 - 7 } & $\mathrm{f}_{1}()$. & $\mathrm{f}_{2}()$. & $\mathrm{f}_{3}()$. & $\mathrm{f}_{4}()$. & $\mathrm{f}_{5}()$. & $\mathrm{f}_{6}()$. \\
\hline $\mathrm{a}_{1}$ & $\mathrm{f}_{1}\left(\mathrm{a}_{1}\right)$ & $\mathrm{f}_{2}\left(\mathrm{a}_{1}\right)$ & $\mathrm{f}_{3}\left(\mathrm{a}_{1}\right)$ & $\mathrm{f}_{4}\left(\mathrm{a}_{1}\right)$ & $\mathrm{f}_{5}\left(\mathrm{a}_{1}\right)$ & $\mathrm{f}_{6}\left(\mathrm{a}_{1}\right)$ \\
\hline $\mathrm{a}_{2}$ & $\mathrm{f}_{1}\left(\mathrm{a}_{2}\right)$ & $\mathrm{f}_{2}\left(\mathrm{a}_{2}\right)$ & $\mathrm{f}_{3}\left(\mathrm{a}_{2}\right)$ & $\mathrm{f}_{4}\left(\mathrm{a}_{2}\right)$ & $\mathrm{f}_{5}\left(\mathrm{a}_{2}\right)$ & $\mathrm{f}_{6}\left(\mathrm{a}_{2}\right)$ \\
\hline$\ldots$ & $\ldots$ & $\ldots$ & $\ldots$ & $\ldots$ & $\ldots$ & $\ldots$ \\
\hline $\mathrm{a}_{\mathrm{i}}$ & $\mathrm{f}_{1}\left(\mathrm{a}_{\mathrm{i}}\right)$ & $\mathrm{f}_{2}\left(\mathrm{a}_{\mathrm{i}}\right)$ & $\mathrm{f}_{3}\left(\mathrm{a}_{\mathrm{i}}\right)$ & $\mathrm{f}_{4}\left(\mathrm{a}_{\mathrm{i}}\right)$ & $\mathrm{f}_{5}\left(\mathrm{a}_{\mathrm{i}}\right)$ & $\mathrm{f}_{6}\left(\mathrm{a}_{\mathrm{i}}\right)$ \\
\hline$\ldots$ & $\ldots$ & $\ldots$ & $\ldots$ & $\ldots$ & $\ldots$ & $\ldots$ \\
\hline $\mathrm{a}_{\mathrm{n}}$ & $\mathrm{f}_{1}\left(\mathrm{a}_{\mathrm{n}}\right)$ & $\mathrm{f}_{2}\left(\mathrm{a}_{\mathrm{n}}\right)$ & $\mathrm{f}_{3}\left(\mathrm{a}_{\mathrm{n}}\right)$ & $\mathrm{f}_{4}\left(\mathrm{a}_{\mathrm{n}}\right)$ & $\mathrm{f}_{5}\left(\mathrm{a}_{\mathrm{n}}\right)$ & $\mathrm{f}_{6}\left(\mathrm{a}_{\mathrm{n}}\right)$ \\
\hline
\end{tabular}

Sumber : Daihani, 2001

Keterangan:

a. a1, a2, ..., ai, an: $\mathrm{n}$ alternatif potensial.

b. $\mathrm{fl}, \mathrm{f} 2, \ldots, \mathrm{fj}, \mathrm{fk}$ : $\mathrm{k}$ kriteria evaluasi.

\section{HASIL DAN PEMBAHASAN}

Tujuan analisa sistem ini adalah agar pihak sekolah STM RAKSANA mendapatkan siswasiswa yang layak untuk masuk kedalam kelas unggulan sesuai dengan prosedur yang telah ditetapkan sebelumnya. Untuk menyeleksi calon siswa yang diterima, pihak sekolah dari STM RAKSANA harus menyeleksi seluruh calon siswa yang mendaftar ke STM RAKSANA untuk diambil beberapa yang layak sehingga dapat dimasukkan kedalam kelas unggulan. STM RAKSANA memiliki 5 kelas untuk 200 calon siswa yang mendaftar dimana setiap kelas terdiri dari 40 siswa, tetapi yang berhasil masuk kedalam 1 kelas unggulan hanya 40 siswa saja dari hasil promethee yang telah dilakukan.

Kriteria yang digunakan sebagai dasar penilaian diperoleh dari Yayasan Pendidikan Raksana Medan, antara lain:

a) Nilai rata-rata raport SMP.

b) Nilai rata-rata Ujian Nasional SMP.

c) Mengikuti ujian seleksi Pengetahuan Umum, Bahasa Indonesia, Bahasa Inggris, Matematika.

\subsection{Analisa Pembagian Kelas Unggulan dengan Metode Promethee}

a) Untuk dapat menentukan keputusan yang terbaik ada beberapa metode yang dapat digunakan untuk membangun sebuah sistem pendukung keputusan salah satunya adalah Promethee. Metode promethee termasuk kedalam kelompok pemecahan Multi Criteria Decision Making (MCDM) atau pengambilan keputusan kriteria majemuk yang merupakan disiplin ilmu yang sangat penting dalam pengambilan keputusan atas suatu masalah yang memiliki lebih dari satu kriteria (multikriteria).

b) Promethee merupakan salah satu ranking dalam Multiple Criteria Decision Making (MCDM). Pengertia dari metode Promethee adalah sebagai berikut:

c) "Promethee adalah suatu metode menentuan urutan (prioritas) dalam analisa multikriteria. Masalah pokoknya adalah kesederhanaan, kejelasan, dan kestabilan. Dugaan dari dominasi kriteria yang digunakan dalam promethee adalah pengunaan nilai dalam hubungan outranking. Semua parameter yang dinyatakan mempunyai pengaruh nyata menurut pandangan ekonomi. 
Berikut adalah contoh dari menggunakan metode promethee dengan kriteria dan bobot sebagai berikut pada STM RAKSANA Medan.

Tabel 2. Tabel Kriteria dan Nilai Bobot

\begin{tabular}{|l|l|}
\hline Kriteria/alternative & Bobot (\%) \\
\hline Nilai rata-rata raport SMP & $30 \%$ \\
\hline Nilai rata-rata Ujian Nasional SMP & $30 \%$ \\
\hline Nilai rata-rata seleksi & $40 \%$ \\
\hline
\end{tabular}

Berikut adalah table Kriteria setelah mendapat nilai dari 6 contoh calon siswa yang mendaftar pada STM RAKSANA Medan. Setelah mendapatkan nilai dari masing-masing calon siswa akan dilanjutkan dengan menghitung perbandingan nilai tiap kriteria sehingga akan didapat selisih $\mathrm{H}(\mathrm{d})$ dari kriteria dan index preferen.

Tabel 3. Tabel Kriteria

\begin{tabular}{|l|l|l|l|l|l|l|}
\hline Kriteria/alternative & A & B & C & D & E & F \\
\hline Nilai rata-rata raport SMP & 70 & 70 & 70 & 70 & 70 & 70 \\
\hline Nilai rata-rata Ujian Nasional SMP & 78 & 80 & 90 & 79 & 74 & 71 \\
\hline Nilai rata-rata seleksi & 65 & 67 & 85 & 88 & 80 & 82 \\
\hline
\end{tabular}

Keterangan :

A : Alfa; B : Brafo; C : Charli; D : Dora ; E : Elang; F : Fara

Menghitung nilai $\mathrm{H}(\mathrm{d})$ :

$f(X 1, X 2) \rightarrow d=f(a)-f(b)$

Untuk f:

$\mathrm{f} 1=$ Nilai rata-rata raport SMP

f2= Nilai rata-rata Ujian Nasional SMP

$\mathrm{f} 3=$ Nilai rata-rata ujian seleksi

$\mathrm{d}=$ selisih nilai antara 2 perbandingan

$\mathrm{f} 1=$ Nilai rata-rata raport $\mathrm{SMP} \mathrm{fl}(\mathrm{A}, \mathrm{B}) \rightarrow \mathrm{d}=$ $f(a)-f(b)$

$$
\begin{aligned}
\mathrm{d} & =70-70 \\
\mathrm{~d} & =0
\end{aligned}
$$

maka $\mathrm{H}(\mathrm{d})=1$

$$
\begin{aligned}
\mathrm{fl}(\mathrm{B}, \mathrm{A}) & \rightarrow \mathrm{d}=\mathrm{f}(\mathrm{b})-\mathrm{f}(\mathrm{a}) \\
\mathrm{d} & =70-70 \\
\mathrm{~d} & =0
\end{aligned}
$$

$\operatorname{maka} \mathrm{H}(\mathrm{d})=1$

f2 = Nilai rata-rata Ujian Nasional SMP

$$
\begin{gathered}
\mathrm{f} 2(\mathrm{~A}, \mathrm{~B}) \rightarrow \mathrm{d}=\mathrm{f}(\mathrm{a})-\mathrm{f}(\mathrm{b}) \\
\mathrm{d}=78-80 \\
\mathrm{~d}=-2 \\
\text { maka } \mathrm{H}(\mathrm{d})=0 \\
\mathrm{f} 2(\mathrm{~B}, \mathrm{~A}) \rightarrow \mathrm{d}=\mathrm{f}(\mathrm{b})-\mathrm{f}(\mathrm{a}) \\
\mathrm{d}=80-78 \\
\mathrm{~d}=2 \\
\text { maka } \mathrm{H}(\mathrm{d})=1
\end{gathered}
$$

$$
\begin{aligned}
& \text { f3 = Nilai rata-rata seleksi } \\
& \mathrm{f} 3(\mathrm{~A}, \mathrm{~B}) \rightarrow \mathrm{d}=\mathrm{f}(\mathrm{a})-\mathrm{f}(\mathrm{b}) \\
& d=65-67 \\
& \mathrm{~d}=-2 \\
& \text { maka } \mathrm{H}(\mathrm{d})=0 \\
& \mathrm{f} 3(\mathrm{~B}, \mathrm{~A}) \rightarrow \mathrm{d}=\mathrm{f}(\mathrm{b})-\mathrm{f}(\mathrm{a}) \\
& d=67-65 \\
& \mathrm{~d}=2
\end{aligned}
$$

maka $\mathrm{H}(\mathrm{d})=1$

f1 = Nilai rata-rata raport SMP

$$
\begin{aligned}
\mathrm{fl}(\mathrm{A}, \mathrm{C}) \rightarrow \mathrm{d}=\mathrm{f}(\mathrm{a})-\mathrm{f}(\mathrm{c}) & \\
\mathrm{d} & =70-70 \\
\mathrm{~d} & =0 \\
\operatorname{maka} \mathrm{H}(\mathrm{d}) & =1 \\
\mathrm{fl}(\mathrm{C}, \mathrm{A}) & \rightarrow \mathrm{d}=\mathrm{f}(\mathrm{c})-\mathrm{f}(\mathrm{a}) \\
\mathrm{d} & =70-70 \\
\mathrm{~d} & =0
\end{aligned}
$$

$\operatorname{maka} \mathrm{H}(\mathrm{d})=1$

f2 = Nilai rata-rata Ujian Nasional SMP

$$
\begin{aligned}
& \mathrm{f} 2(\mathrm{~A}, \mathrm{C}) \rightarrow \mathrm{d}=\mathrm{f}(\mathrm{a})-\mathrm{f}(\mathrm{c}) \\
& \mathrm{d}=78-90 \\
& \mathrm{~d}=-12 \\
& \begin{aligned}
\text { maka } \mathrm{H}(\mathrm{d}) & =0 \\
\mathrm{f} 2(\mathrm{C}, \mathrm{A}) & \rightarrow \mathrm{d}=\mathrm{f}(\mathrm{c})-\mathrm{f}(\mathrm{a}) \\
\mathrm{d} & =90-78
\end{aligned}
\end{aligned}
$$


$\mathrm{d}=12$

maka $\mathrm{H}(\mathrm{d})=1$

f3 = Nilai rata-rata seleksi

$\mathrm{f} 3(\mathrm{~A}, \mathrm{C}) \rightarrow \mathrm{d}=\mathrm{f}(\mathrm{a})-\mathrm{f}(\mathrm{c})$

$\mathrm{d}=65-85$

$\mathrm{d}=-20$

maka $\mathrm{H}(\mathrm{d})=0$

$$
\begin{aligned}
\mathrm{f} 3(\mathrm{C}, \mathrm{A}) & \rightarrow \mathrm{d}=\mathrm{f}(\mathrm{c})-\mathrm{f}(\mathrm{a}) \\
\mathrm{d} & =85-65 \\
\mathrm{~d} & =20
\end{aligned}
$$

maka $\mathrm{H}(\mathrm{d})=1$

f1 = Nilai rata-rata raport SMP

$$
\begin{aligned}
\mathrm{fl}(\mathrm{A}, \mathrm{D}) & \rightarrow \mathrm{d}=\mathrm{f}(\mathrm{a})-\mathrm{f}(\mathrm{d}) \\
\mathrm{d} & =70-70 \\
\mathrm{~d} & =0
\end{aligned}
$$

maka $\mathrm{H}(\mathrm{d})=1$

$$
\begin{aligned}
\mathrm{f} 1(\mathrm{D}, \mathrm{A}) & \rightarrow \mathrm{d}=\mathrm{f}(\mathrm{d})-\mathrm{f}(\mathrm{a}) \\
\mathrm{d} & =70-70 \\
\mathrm{~d} & =0
\end{aligned}
$$

maka $\mathrm{H}(\mathrm{d})=1$

f2 = Nilai rata-rata Ujian Nasional SMP

$$
\begin{aligned}
\mathrm{f} 2(\mathrm{~A}, \mathrm{D}) & \rightarrow \mathrm{d}=\mathrm{f}(\mathrm{a})-\mathrm{f}(\mathrm{d}) \\
\mathrm{d} & =78-79 \\
\mathrm{~d} & =-1 \\
\text { maka H(d) }=0 & \\
\mathrm{f} 2(\mathrm{D}, \mathrm{A}) & \rightarrow \mathrm{d}=\mathrm{f}(\mathrm{d})-\mathrm{f}(\mathrm{a}) \\
\mathrm{d} & =79-78 \\
\mathrm{~d} & =1
\end{aligned}
$$

$\operatorname{maka} \mathrm{H}(\mathrm{d})=1$ f3 = Nilai rata-rata seleksi

$$
\begin{aligned}
\mathrm{f} 3(\mathrm{~A}, \mathrm{D}) \rightarrow \mathrm{d}=\mathrm{f}(\mathrm{a})-\mathrm{f}(\mathrm{d}) \\
\mathrm{d}=65-88 \\
\mathrm{~d}=-23
\end{aligned}
$$

$\operatorname{maka} \mathrm{H}(\mathrm{d})=0$

$$
\begin{aligned}
\mathrm{f} 3(\mathrm{D}, \mathrm{A}) & \rightarrow \mathrm{d}=\mathrm{f}(\mathrm{d})-\mathrm{f}(\mathrm{a}) \\
\mathrm{d} & =88-65 \\
\mathrm{~d} & =23
\end{aligned}
$$

maka $\mathrm{H}(\mathrm{d})=1$

dan seterusnya hingga

$\mathrm{f} 2$ = Nilai rata-rata Ujian Nasional SMP

$$
\begin{aligned}
\mathrm{f} 2(\mathrm{E}, \mathrm{F}) \rightarrow \mathrm{d}=\mathrm{f}(\mathrm{e})-\mathrm{f}(\mathrm{f}) \\
\mathrm{d}=74-71 \\
\mathrm{~d}=3
\end{aligned}
$$

$\operatorname{maka} \mathrm{H}(\mathrm{d})=1$

$$
\begin{aligned}
\mathrm{f} 2(\mathrm{~F}, \mathrm{E}) & \rightarrow \mathrm{d}=\mathrm{f}(\mathrm{f})-\mathrm{f}(\mathrm{e}) \\
\mathrm{d} & =71-74 \\
\mathrm{~d} & =-3
\end{aligned}
$$

maka $\mathrm{H}(\mathrm{d})=0$

f3 = Nilai rata-rata seleksi

$$
\begin{aligned}
& \mathrm{f} 3(\mathrm{E}, \mathrm{F}) \rightarrow \mathrm{d}=\mathrm{f}(\mathrm{e})-\mathrm{f}(\mathrm{f}) \\
& \mathrm{d}=80-82 \\
& \mathrm{~d}=-2 \\
& \mathrm{f} 3(\mathrm{~F}, \mathrm{E}) \rightarrow \mathrm{d}=\mathrm{f}(\mathrm{f})-\mathrm{f}(\mathrm{e}) \\
& \mathrm{d}=82-80 \\
& \mathrm{~d}=2
\end{aligned}
$$

maka $\mathrm{H}(\mathrm{d})=1$

a. Langkah selanjutnya menghitung index multikriteria

Setelah seluruh hasil H(d) dari setiap calon siswa yang mendaftar pada STM RAKSANA Medan akan dijumlan kan dan dibagi dengan jumlah kriteria.
$(\mathrm{A}, \mathrm{B})=1 / 3(1+0+0+1+0+1)=1$
$(\mathrm{B}, \mathrm{A})=1 / 3(1+1+1+0+1+0)=1.33$
$(\mathrm{A}, \mathrm{C})=1 / 3(1+0+0+1+0+0)=0.66$
$(C, A)=1 / 3(1+1+1+0+1+1)=1.66$
$(\mathrm{A}, \mathrm{D})=1 / 3(1+0+0+1+0+0)=0.66$
$(\mathrm{D}, \mathrm{A})=1 / 3(1+1+1+0+1+1)=1.66$
$(\mathrm{A}, \mathrm{E})=1 / 3(1+1+0+1+0+0)=1$
$(\mathrm{E}, \mathrm{A})=1 / 3(1+0+1+0+1+1)=1.33$
$(\mathrm{A}, \mathrm{F})=1 / 3(1+1+0+1+0+0)=1$
$(\mathrm{F}, \mathrm{A})=1 / 3(1+0+1+0+1+1)=1.33$
$(\mathrm{B}, \mathrm{C})=1 / 3(1+0+0+1+1+0)=1$
$(C, B)=1 / 3(1+1+1+0+0+1)=1.33$
$(\mathrm{B}, \mathrm{D})=1 / 3(1+1+0+1+1+0)=1.33$
$(\mathrm{D}, \mathrm{B})=1 / 3(1+0+1+0+0+1)=1$ 

$(\mathrm{B}, \mathrm{E})=1 / 3(1+1+0+1+1+0)=1.33$
$(\mathrm{E}, \mathrm{B})=1 / 3(1+0+1+0+0+1)=1$
$(\mathrm{B}, \mathrm{F})=1 / 3(1+1+0+1+1+0)=1.33$
$(\mathrm{F}, \mathrm{B})=1 / 3(1+0+1+0+0+1)=1$
$(\mathrm{C}, \mathrm{D})=1 / 3(1+1+0+0+0+1)=1$
$(\mathrm{D}, \mathrm{C})=1 / 3(1+0+1+1+1+0)=1.33$
$(C, E)=1 / 3(1+1+1+1+1+0)=1.66$
$(\mathrm{E}, \mathrm{C})=1 / 3(1+0+0+0+0+1)=0.66$
$(\mathrm{C}, \mathrm{F})=1 / 3(1+1+1+0+1+1)=1.66$
$(\mathrm{F}, \mathrm{C})=1 / 3(1+0+0+1+0+0)=0.66$
$(\mathrm{D}, \mathrm{E})=1 / 3(1+1+1+1+1+0)=1.66$
$(E, D)=1 / 3(1+0+0+0+0+1)=0.66$
$(\mathrm{D}, \mathrm{F})=1 / 3(1+1+1+0+1+0)=1.33$
$(F, D)=1 / 3(1+0+0+1+0+1)=1$
$($ E.F $)=1 / 3(1+1+0+0+1+1)=1.33$
$(\mathrm{F}, \mathrm{E})=1 / 3(1+0+1+1+0+0)=1$

Berikut adalah tabel Promethe Tahap I setelah mendapat perhitungan dari penjumlahan nilai perbandingan $\mathrm{H}(\mathrm{d})$ atau setelah mendapat perhitungan dari index multikriteria.

Tabel 4. Promethee Tahap 1

\begin{tabular}{|l|l|l|l|l|l|l|}
\hline & A & B & C & D & E & F \\
\hline A & - & 1 & 0.66 & 0.66 & 1 & 1 \\
\hline B & 1.33 & - & 1 & 1.33 & 1.33 & 1.33 \\
\hline C & 1.66 & 1.33 & - & 1 & 1.66 & 1.66 \\
\hline D & 1.66 & 1 & 1.33 & - & 1.66 & 1.33 \\
\hline E & 1.33 & 1 & 0.66 & 0.66 & - & 1.33 \\
\hline F & 1.33 & 1 & 0.66 & 1 & 1 & - \\
\hline
\end{tabular}

b. Selanjutnya menghitung Leaving Flow

Langkah selanjutnya adalah mencari nilai Leaving Flow dengan melihat dari data table Proethee

Tahap I

$$
\begin{array}{ll}
\mathrm{A}=1 /(3-1)(1+0.66+0.66+1+1) & =2.16 \\
\mathrm{~B}=1 /(3-1)(1.33+1+1.33+1.33+1.33) & =3.16 \\
\mathrm{C}=1 /(3-1)(1.66+1.33+1+1.66+1.66) & =3.65 \\
\mathrm{D}=1 /(3-1)(1.66+1+1.33+1.66+1.33) & =3.49 \\
\mathrm{E}=1 /(3-1)(1.33+1+0.66+0.66+1.33) & =2.49 \\
\mathrm{~F}=1 /(3-1)(1.33+1+0.66+1+1) & =2.49
\end{array}
$$

c. Menghitung Entering Flow

Langkah selanjutnya adalah mencari nilai Entering Flow dengan melihat pada tabel Promethee Tahap I

$$
\begin{array}{ll}
\mathrm{A}=1 /(3-1)(1.33+1.66+1.66+1.33+1.33) & =3.65 \\
\mathrm{~B}=1 /(3-1)(1+1.33+1+1+1) & =2.66 \\
\mathrm{C}=1 /(3-1)(0.66+1+1.33+0.66+0.66) & =2.15 \\
\mathrm{D}=1 /(3-1)(0.66+1.33+1+0.66+1) & =2.82 \\
\mathrm{E}=1 /(3-1)(1+1.33+1.66+1.66+1) & =3.28 \\
\mathrm{~F}=1 /(3-1)(1+1.33+1.66+1.33+1.33) & =3.32
\end{array}
$$

d. Menghitung Net Flow 
Langkah selanjutnya adalah mencari nilai net flow didapat dari selisih antara Leaving Flow dan Entering Flow

$$
\begin{aligned}
& A=2.16-3.65=-1.49 \\
& B=3.16-2.66=0.5 \\
& C=3.65-2.15=1.5 \\
& D=3.49-2.82=0.67 \\
& E=2.49-3.28=-0.79 \\
& F=2.49-3.32=-0.83
\end{aligned}
$$

Berikut adalah table Promethee Tahap II setelah mendaptkan selisih antara Leaving Flow dan Entering Flow Tabel 5. Promethee Tahap II

\begin{tabular}{|c|c|c|}
\hline Alternatif & Net Flow & Ranking \\
\hline A & -1.49 & 6 \\
\hline B & 0.5 & 3 \\
\hline C & 1.5 & 1 \\
\hline D & 0.67 & 2 \\
\hline E & -0.79 & 5 \\
\hline F & -0.83 & 4 \\
\hline
\end{tabular}

Berdasarkan nilai Net Flow dari Tabel 5 diperoleh nilai ranking berdasarkan karakter net flow, sebagai berikut:
a. $\quad \mathrm{C}=$ Charli, menempati urutan I
b. $\mathrm{D}=$ Dora, menempati urutan II
c. $\quad \mathrm{B}=$ Brafo, menempati urutan III
d. $\mathrm{F}=$ Farah, menempati urutan IV
e. $\mathrm{E}=$ Elang, menempati urutan $\mathrm{V}$
f. $\quad A=$ Alfa, menempati urutan VI

\section{KESIMPULAN}

Kesimpulan yang dapat diambil berdasarkan rumusan masalah dan tujuan penelitian dari skripsi ini adalah sebagai berikut :

1. Proses penentuan pembobotan berdasarkan dari penelitian kriteria yang telah ditentukan dari pihak STM RAKSANA Medan.

2. Proses pengimplementasian Sistem Pendukung Keputusan (SPK) pembagian kelas unggulan ini menggunakan metode promethee sehingga urutan dari calon siswa yang mendaftar mulai dari yang tertinggi sampai dengan yang terendah dengan dilakukannya perhitungan nilai leaving flow, entering flow, dan net flow.

3. Sistem ini dirancang sebagai pendukung keputusan pembagian kelas unggulan siswa baru di STM Raksana Medan.

\section{DAFTAR PUSTAKA}

[1] Tonni Limbong, "PENDIDIKAN BERBASIS IT DAN ETIKANYA," Jayapangus Press, vol. 1, no. 1, pp. 52-79, 2018.

[2] I. Ketut et al., "PARADIGMA PEDIDIKAN BERMUTU BERBASIS TEKNOLOGI PENDIDIKAN," Mar. 2018.

[3] G. Ghufron, "Revolusi Industri 4.0: Tantangan, Peluang, Dan Solusi Bagi Dunia Pendidikan," 2018. 
[4] C. Purnamaningsih, R. Saptono, and A. Aziz, "Pemanfaatan Metode K-Means Clustering dalam Penentuan Penjurusan Siswa SMA," Jurnal Teknologi \& Informasi ITSmart, vol. 3, no. 1, p. 27, 2016, doi: 10.20961/its.v3i1.644.

[5] T. Magrisa, K. D. K. Wardhani, and M. R. A. Saf, "Implementasi Metode SMART pada Sistem Pendukung Keputusan Pemilihan Kegiatan Ekstrakurikuler untuk Siswa SMA," Informatika Mulawarman : Jurnal Ilmiah Ilmu Komputer, 2018. http://ejournals.unmul.ac.id/index.php/JIM/article/view/648/pdf (accessed May 29, 2021).

[6] J. Purnama, "SISTEM PENDUKUNG KEPUTUSAN SELEKSI PENERIMAAN SISWA BARU MENGGUNAKAN METODE SIMPLE ADDITIVE WEIGHTING (SAW) (Studi Kasus : SMA Negeri 01 Kalirejo).” [Online]. Available: www.stmikpringsewu.ac.id

[7] A. Rikki, M. Maebun, and J. R. Siregar, "Sistem Pendukung Keputusan Penerimaan Karyawan Dengan Metode SAW Pada PT. Karya Sahata Medan," Journal of Informatics Pelita Nusantara, 2016.

[8] Kusrini, Konsep dan Aplikasi Sistem Pendukung Keputusan. 2007.

[9] T. Limbong and R. Limbong, "IMPLEMENTASI METODE SIMPLE ADDITIVE WEIGHTING DALAM PEMILIHAN BIBIT UNTUK BUDIDAYA IKAN MAS," Jurnal Teknik Informatika Kaputama (JTIK), vol. 2, no. 1, pp. 115-122, 2018, doi: 10.13140/RG.2.2.10083.45609.

[10] T. Limbong et al., Sistem Pendukung Keputusan: Metode \& Implementasi. Yayasan Kita Menulis, 2020.

[11] S. Arikunto, "Metodelogi penelitian," Yogyakarta: Bina Aksara, 2006.

[12] T. Limbong et al., Sistem Pendukung Keputusan : Metode dan Implementasi. Medan: Yayasan Kita Menulis, 2020.

[13] N. S. Atmaja and S. P. Keputusan, “Attribution-NonCommercial 4.0 International. Some rights reserved Sistem Pendukung Keputusan Sistem Pendukung Keputusan Pemilihan Jurusan Menggunakan Metode PROMETHEE (Studi Kasus : SMK Negeri 6 Medan),” vol. 5, no. 2, 2021, doi: 10.30743/infotekjar.v5i2.3575.

[14] I. Wahyu Pratama, "SISTEM PENDUKUNG KEPUTUSAN EVALUASI KINERJA DOSEN DENGAN METODE TECHNIQUE FOR ORDER BY SIMILARITY TO IDEAL SOLUTION (TOPSIS) \& PREFERENCE RANKING ORGANIZATION FOR EVALUATION(PROMETHEE),” Jul. 2018. Accessed: May 31, 2021. [Online]. Available: https://jurnal.dcc.ac.id/index.php/JC/article/view/62

[15] R. O. Siregar and D. Irmayani, "JURNAL MEDIA INFORMATIKA BUDIDARMA Penerapan Metode Promethee Dalam Sistem Pendukung Keputusan Penetapan Penerima Kartu Indonesia Sehat (KIS)," JURNAL MEDIA INFORMATIKA BUDIDARMA, vol. 5, no. 2, pp. 739-745, Apr. 2021, doi: 10.30865/mib.v5i2.2948. 